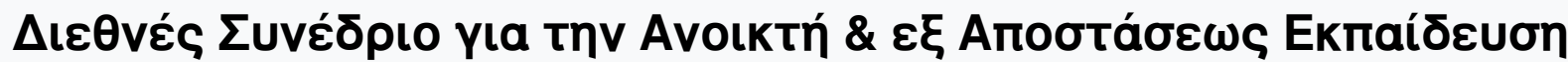

Tón. 5, Ap. 1A (2009)

Open and Distance Education for Global Collaboration \& Educational Development

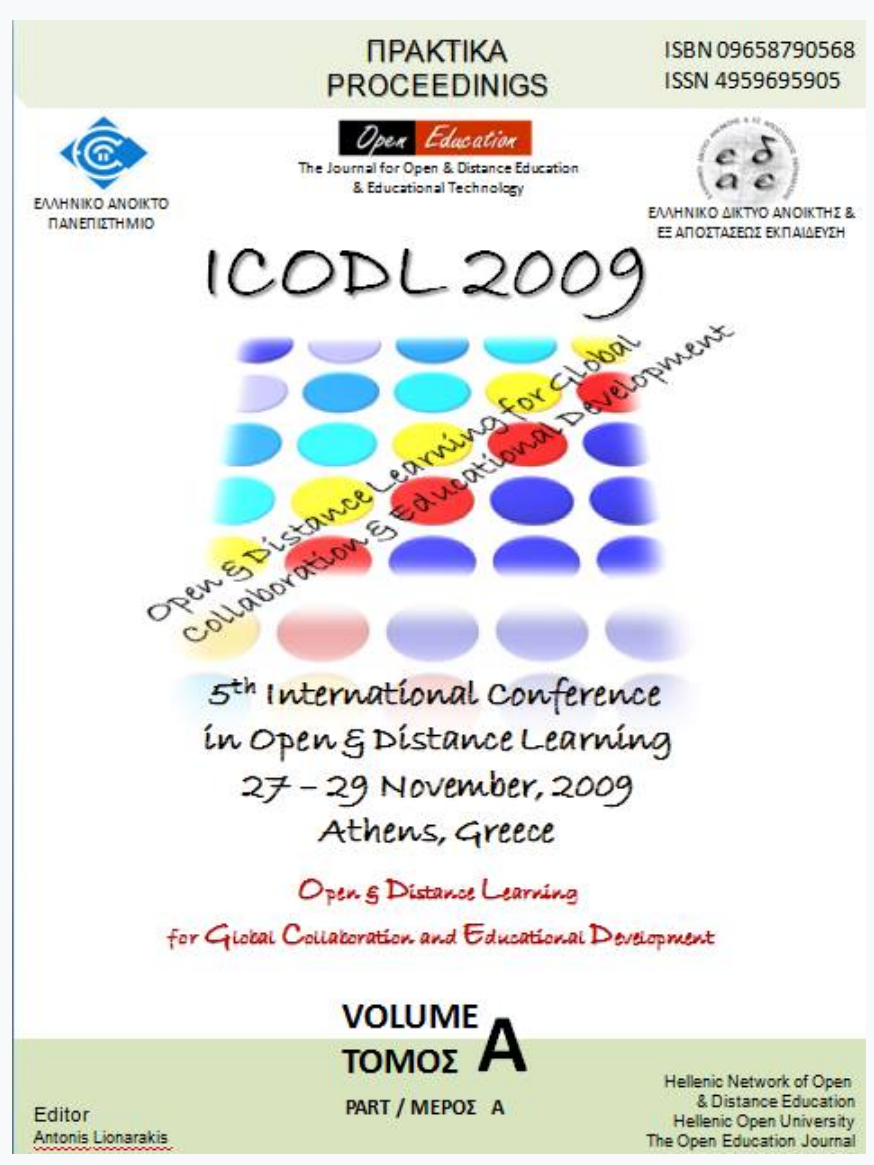

The roles of teachers and students in computer supported collaborative learning among distance learners

Siti Hamin STAPA

doi: $10.12681 /$ icodl.484 


\title{
The roles of teachers and students in computer supported collaborative learning among distance learners
}

\author{
Siti Hamin STAPA \\ institution: universiti kebangsaan malaysia \\ lecturer \\ sitihami@ukm.my
}

\begin{abstract}
The effectiveness of group learning in asynchronous distributed learning groups depends on the social interaction that take place. This social interaction affects both cognitive and socio-emotional processes that take place during learning, group forming, establishment of group structures and group dynamics. Individual differences play an important role in establishing social interaction in a virtual learning environment. This article will explore the roles of teachers and students on computer supported collaborative learning among adult distance learners. Theoretical framework that will be used is based upon an ecological approach to social interaction, centering on the concept of social affordances, the concept of sociability of CSCL environments and social presence theory. 130 students from an open university in Malaysia were asked to answer the questionnaire designed for the study. These learners were required to participate in online discussions as part of their course requirement. The findings show that individual differences, motivation, attitude play important roles in online interaction. Teachers' roles, too, were found to be very important in enhancing collaboration among the distance learners. Teachers' roles include preparing teaching and learning activities for the students. Learning in a hightech, global environment presents new roles and responsibilities for both teacher and learner.
\end{abstract}

\section{Introduction}

Collaboration is the act of working together to produce a piece of work. Collaborative learning deals with instructional methods that seek to promote learning through collaborative efforts among students working on a given task. Class based CL fits well with the philosophy of teaching: working together, building together, learning together, changing together and improving together. Collaborative culture is very much related to team work, a fact that demands new social abilities. This collaborative competence matches a generalised idea of abandoning the conception of an individualistic and isolated job and moves towards more collaborative cultures. Computer-mediated CL (CSCL) has an impact on the development of deep thinking about ideas as students are engaged in writing rather than talking. By doing so, they have more time to think about the responses; able to engage in developing arguments; have time to follow up references and read literature, etc. The purpose of CSCL is to scaffold or support students in learning together effectively. It is based on the promise that computer supported systems can support and facilitate group process and dynamics in ways that are not achievable by face-to-face, but it is not designed to replace face-to-face communication. 


\section{Computer supported collaborative learning (cscl)}

Depending on the type of collaborative tasks to perform Computer Supported Collaborative Learning (CSCL) could be employed to address concept learning, problem solving and designing. CSCL focuses on what is being communicated and is used in the educational setting. The purpose of CSCL is to scaffold or support students in learning together effectively.

\section{THEORIES OF CSCL}

Many theories contribute our understanding of the computer supported collaborative learning. These theories are sociocultural theory (based on Vygotsky's intersubjectiveness and Zone of Proximal Development). Constructivism theory, selfregulation theory (skill, will, and execute control), situated cognition, cognitive apprenticeship, problem-based learning (Cognition \& Technology Group at Vanderbilt), Spiro et al.'s $(1988,1990)$ cognitive flexibility theory, and Salomon et al.'s (1992) distributed cognition ("effect of" and "effect with" technology). These theories are based on the same underlying assumptions that individual are active agents and that they are purposefully seeking and constructing knowledge within a meaningful context.

i) Vygotsky's Sociocultural Theory - Human intelligence originates in our society or culture, and individual cognitive gain through interpersonal (interaction with social environment) than intrapersonal (internalization)- the idea of ZPD

ii) Constructivism Theory - Learning emphasizes on meaning-making through active participation in socially, culturally, historically, and politically situated context.

iii) Problem-Base Learning/Anchored Instruction - Learning begins with a problem to be solved rather than content to be mastered.

iv) Distributed Cognition - The interaction among individuals, environment, and cultural artifacts. Development and growth of cognition of individuals should not be isolated events.

v) Cognitive Flexibility Theory - Spiro's Theory (1988) and criss-crosses landscape theory approaches address important issue in transfer, how general knowledge is transferred in ill-structured domains.

vi) Cognitive Apprenticeship - Wilson \& Cole (1994) describe the core characteristics of cognitive apprenticeship model: heuristic content, situated learning, modelling, coaching, articulation, reflection, exploration, and order in increasing complexity.

vii) Situated Cognition - Thinking is both physically and socially situated that problem tasks can be significantly shaped and changed by the tools made available and the social interactions that take place during problem solving.

viii) Self-Regulated Learning - . The learner is the initiator of the learning process.

\section{Previous studies in cscl}

A project by Simons (2004) has explored the effectiveness of computer-supported collaborative learning (CSCL) networks. Computer-supported collaborative learning (CSCL) requires teachers and students to adopt an educational philosophy that focuses on 'knowledge building' rather than 'knowledge reproduction' as the main learning activity. Computer support does add value by: 
i) the easier organization in the classroom of collaborative learning,

ii) better visibility of collaboration processes,

iii) making communication patterns visible,

iv) making types of thinking visible,

v) learning to build knowledge and meaning collectively,

vi) building connections with practice, and

v) opening new forms of collaboration.

There were significant advantages in using computer-supported collaborative learning (CSCL) in languages and in process-oriented measures. ACOT's two years (1986-87) study indicates that attitudes towards self and learning showed improvement. Sherry \& Myers (1996) study group dynamics of graduate students collaboratively group becomes a self-reflective. King (1989) observes verbal interaction and problem solving behaviour of small collaborative peer group working on CAI tasks. He finds successful group involved in more tasks talks than social talks. Weir (1992) indicates that both teachers and researchers find that students who work together on "real world problems show increased motivation, deeper understanding of the concept of an increased willingness to tackle difficult questions that they cannot answer alone."

\section{Roles of teachers and students}

Teachers should share their knowledge and experience with students by providing consulting, helping, directing, and advising. Distance Education embraces whole of the student activity, responsibility and willingness for formulating and asking relevant questions and seeking answers. Many Distance Education programmes use discussion and question-answer type media, or decisions based on short scenarios or simulations. The main consideration is here to define and measure role effectiveness of teacherstudent communication on learning at a distance (Willis, 2002). Distance education is new technological power for developing a dynamic self-concept for students. The constructivist approach changes the role of educators. Distance Education emulates this approach by leading the students (learner) to develop his or her own strategies, objectives, evaluation, implementation under guidance of a teachers (Gibson, 1997).

The changing roles of students and teachers in distance education are influencing classical education standards and pedagogy. According to research findings (Holmberg, 1995, Harry et.al.,1993) on the roles of the students' in distance education are:

1. Be disciplined and on task

2. Consult with and seek guidance from advisors through required access methods

3. Assume responsibility for your own learning

4. Develop effective interaction with teachers and counselors (like classical learning)

5. Evaluate and judge your own performance

6. Combat prejudice and communication barriers

According to research findings (Holmberg, 1995, Harry et.al.,1993) on the roles of the teachers in distance education are:

1. Assume responsibility for preparation and presentation of learning tasks

2. Immediately consult with students to correct problems and keep them on task 
3. Be aware of student needs and wishes; respond promptly to communications and tests

4. Build student motivation

5. Combat prejudice of communicational barriers

6. Establish an effective environment for student-teacher and student-student interaction

Research provides data to compare effectiveness of the teaching and learning in a great variety of situations. Learning in a high-tech, global environment presents new roles and responsibilities for both teacher and learner. In addition; there is a radical change in construction and delivery of course content. Media to facilitate interaction between and among learners, teachers, and content increases the opportunity for indepth and meaningful learning (Gibson, 1997). Constructivist techniques support learning and teaching, self-development and self evaluation (İşman, 1999). Constructivism is an integral part of distance education. The focus is on the student and his active role in learning supported by technology.

\section{Attitude, motivation and anxiety}

Gardner and Lambert (1972) introduced the notions of instrumental and integrative motivation. Instrumental motivation refers to the learner's desire to learn a language for utilitarian purposes (such as employment or travel or exam purposes) in the context of language learning. On the other hand, integrative motivation refers to the desire to learn a language to integrate successfully into the target language community. In later research studies, Crookes and Schmidt (1991), and Gardner and Tremblay (1994) explored four other motivational orientations: (a) reason for learning, (b) desire to attain the learning goal, (c) positive attitude toward the learning situation, and (d) effortful behaviour.

Many theorists and researchers have found that it is important to recognize the construct of motivation not as a single entity but as a multi-factorial one. Oxford and Shearin (1994) analyzed a total of 12 motivational theories or models, including those from socio-psychology, cognitive development, and socio-cultural psychology, and identified six factors that impact motivation in language learning:

- Attitudes (i.e., sentiments toward the learning community and the target language)

- Beliefs about self (i.e., expectancies about one's attitudes to succeed, selfefficacy, and anxiety)

- Goals (perceived clarity and relevance of learning goals as reasons for learning)

- Involvement (i.e., extent to which the learner actively and consciously participates in the language learning process)

- Environmental support (i.e., extent of teacher and peer support, and the integration of cultural and outside-of-class support into learning experience)

- Personal attributes (i.e., aptitude, age, sex, and previous language learning experience)

\section{Methodology}


The samples selected for this study are 130 students from an open university in Klang Valley. Their ages are from $21-51$ years old. They are doing a part time degree and they attend classes face to face five times per semester. Majority of them are doing degrees in teaching and nursing. As part of the course requirement, they need to participate in an online forum where they can discuss or pose questions to their peers and instructors. The discussions must be related to the course content, examination and assignments. Marks will be awarded to ensure that the students will actively participate in the forum. As distance learners, they need this type of forum to assist them especially when they have problems with their course and they do not meet regularly to discuss face-to-face.

\section{Instrument}

Self-report questionnaire adapted from constructs developed by Kreijns et al 2007 and Gress et al 2007. The questionnaire was administered to 130 distance-education learners doing English language courses in a prominent Open University in Malaysia. The data from the questionnaire was analysed statistically using SPSS.

\section{Results of the Study}

Roles of students: motivation, attitude, anxiety and collaborative experience

Attitude plays the most important role in computer supported collaborative learning among adult distance learners. The mean score for attitude obtained from the questionnaire is 2.99. This finding shows that having positive attitude would make active participation and this will enhance online collaboration. Apart from attitude, motivation also plays a very important role in computer-supported collaborative learning. The mean score for motivation is 2.97. The next important variable is anxiety $(M=2.41)$. The table below shows the result of roles of all the constructs.

\begin{tabular}{|l|r|r|r|}
\hline & anxiety & attitude & motivation \\
\hline $\mathrm{N} \quad$ Valid & 130 & 129 & 130 \\
\multicolumn{1}{|c|}{ Missing } & 1 & 2 & 1 \\
Mean & 2.4119 & 2.9961 & 2.9763 \\
Std. Error of Mean & .03590 & .05315 & .03080 \\
Median & 2.4444 & 3.0000 & 3.0000 \\
Mode & 2.44 & 3.00 & 3.00 \\
Std. Deviation & .40938 & .60362 & .35116 \\
Variance & .168 & .364 & .123 \\
Range & 2.78 & 6.67 & 1.83 \\
Minimum & 1.22 & 1.33 & 2.17 \\
Maximum & 4.00 & 8.00 & 4.00 \\
Sum & 313.55 & 386.50 & 386.92 \\
\hline
\end{tabular}


The items under the construct of attitude includes reading and replying to the messages posted in the online forum as well as their preference to interacting online compared to face-to-face. While items included under the construct of motivation are the participants' willingness to participate in the online discussion, their feelings while interacting with their classmates regardless of the age, ethnic background, career, gender and language proficiency. The items chosen for anxiety are the reasons for not participating in the online discussion for example their poor English language proficiency, their ideas are not good enough and they have no ideas to write.

\section{Roles of teachers: Teachers encouragement and feedback}

Teachers' roles play a very important factor in enhancing collaboration among the distance learners. Teachers' roles include preparing teaching and learning activities for the students. The result of the survey indicate that the activities assigned by the teachers is an important factor in encouraging the participation by the distance learners $(\mathrm{M}=3.08)$. Instructors are expected to give feedback and comments to students' online entries and this is also an important factor in enhancing online participation with the mean score of 3.0. Under the construct of tutors' feedback the items posed are tutors responding regularly, giving useful and encouraging feedback The survey also indicates that students are also expected to respond to the instructors comments in an online collaboration $(\mathrm{M}=3.13)$. Overall, in order to encourage active participation from the distance learners for collaborative projects and assignments the teachers should play active roles too. These include initiating the discussion, giving encouraging comments, answering queries promptly, guiding the readings and correcting language errors. The mean score for teachers' roles is 3.03. Findings of the survey can be seen from the table below:

\begin{tabular}{|l|r|r|r|r|}
\hline & $\begin{array}{c}\text { teaching/learn } \\
\text { ing activities }\end{array}$ & $\begin{array}{c}\text { student } \\
\text { response to } \\
\text { instructors }\end{array}$ & $\begin{array}{c}\text { instructors } \\
\text { feedback to } \\
\text { student }\end{array}$ & $\begin{array}{l}\text { Role of } \\
\text { tutor/instructor }\end{array}$ \\
\hline $\mathrm{N} \quad$ Valid & 129 & 129 & 129 & 126 \\
Missing & 2 & 2 & 2 & 5 \\
Mean & 3.0848 & 3.1357 & 3.0065 & 3.0302 \\
Std. Error of Mean & .03855 & .04145 & .04532 & .03865 \\
Median & 3.0000 & 3.0000 & 3.0000 & 3.0000 \\
Mode & 3.00 & 3.00 & 3.00 & 3.00 \\
Std. Deviation & .43781 & .47084 & .51472 & .43382 \\
Variance & .192 & .222 & .265 & .188 \\
Range & 2.29 & 2.00 & 2.67 & 2.00 \\
Minimum & 1.71 & 2.00 & 1.33 & 2.00 \\
Maximum & 4.00 & 4.00 & 4.00 & 4.00 \\
Sum & 397.94 & 404.50 & 387.83 & 381.80 \\
\hline
\end{tabular}


Research provides data to compare effectiveness of the teaching and learning in a great variety of situations. Learning in a high-tech, global environment presents new roles and responsibilities for both teacher and learner. In addition; there is a radical change in construction and delivery of course content. Media to facilitate interaction between and among learners, teachers, and content increases the opportunity for indepth and meaningful learning (Gibson, 1997).

\section{Teacher Role in encouraging online Collaboration in Distance Education}

1. Teacher promotes learner autonomy and is aware of individual differences.

2. Teacher uses relevant and current information to transmit knowledge. Teacher constantly researches the curriculum and provides concrete up-to-date examples.

3. Teacher gives importance to the thoughts of students and promotes student research, evaluation, discussion, and reporting.

4. Teacher is aware of individual student differences when designing course materials

5. Teacher knows student prerequisite skills and knowledge and uses this foundation to build new knowledge. In addition, the teacher knows how learner can learn.

6. Teacher initiates student-teacher interaction, and has communication and technological skills to effectively implement distance education.

7. Teacher constructs student-centered learning with opportunities for interaction. Students are responsible for learning and responsible for contacting teacher when needed.

8. Teacher collaborates with student in self-development and responsibility.

9. Teacher provides environment, materials, and guidance for collaborative learning, interactive discussion groups, individual learning, and research.

10. Teacher provides prompt and accurate feedback to students to facilitate learning.

\section{Student Role in encouraging online Collaboration in Distance Education}

1. Students use appropriate technology to interact collaboratively with each other and teacher, and use feedback and consultation to develop and refine knowledge, skills, and attitudes.

2. Students are self-responsible for their own learning. They should decide what they want to learn, establish their goal, research and develop their subject.

3. Students research current data to answer questions and solve problems

4. Students learn to solve problems by assessment, data collection, and developing and implementing strategies using relevant information.

5. Students identify communication barriers, their causes, and solutions.

6. Students promote life-long learning and know how to access and use information when instruction is finished.

\section{Conclusion}


This study has many implications to many parties concern. Firstly, to the students, it is a new way of self-study outside the walls of a classroom. Getting information from peers who have better knowledge is a good way for learning to take place (Vygotsky's theory of ZPD). However, they need to have positive attitude and motivation then only they can make the online discussion working for them. As the participants of this study are distance learners, this is an avenue for them to interact with their peers and teachers; where they can discuss issues related to their course. By doing this, they can improve their literacy and cultivate knowledge and cultural understanding besides increase motivation through self-directed, CL and access to technology. As for teachers, they can engage students with fun and real-world learning situation by assigning online projects for the students that will foster cultural awareness. They should focus on teaching with technology and also track students' progress apart from posting homework/activities for students. For parents of students, they can have dialogs with school staff, experience multilingual communication, have confidence that students' tasks are monitored and also understand the online environment. Present day writing classrooms have no boundaries now. CSCL offers global communications where teachers/students are discovering the magic of collaborating with other schools/classes. From around the world teaching and learning are no more within the four walls of the classroom.

\section{References}

Crookes, G., \& Schmidt, R. W. (1991). Motivation: Reopening the research agenda. Language Learning, 41, 469-512

Gress, C.L.Z.et.al., 2007 Measurement and assessment in computer-supported collaborative learning, Computers in Human Behavior, 32, 112-117.

Gardner, R. and W. Lambert (1972) Attitudes and Motivation in Second-Language Learning. Rowley, Ma.: Newbury House

Gardner, R. C., \& Tremblay, P. F. (1994). On motivation, research agendas, and theoretical frameworks. The Modern Language Journal, 78, 359-368.

Harry, K, J. Magnus, Keegan, D (1993) “Distance Education: New Perspectives” Rutledge in London and New York.

Holmberg, B (1995) “Theory and Practice of Distance Education” Rutledge in New York.

Kreijns K et. al, 2007 Measuring perceived sociability of computer-supported collaborative learning environments. Computers and Education 49 (2007), 176-192.

King, A. (1989). Verbal Interaction \& Problem Solving Within the Computer-Assisted Cooperative Learning Groups. Journal of Education Computing Research, 5(1), 1-15.

Oxford, R., \& Shearin, J. (1994). Language learning motivation: Expanding the theoretical framework. The Modern Language Journal, 78, 12-28.

Salomon, G.. \& Perkins, D.N. \& Globerson, T. (1992). Partners in Cognition: Extending Human Intelligence with Intelligent Technologies. Educational Researcher, 20(3), 2-9.

Spiro, R.J., Coulson, R. L., Feltovich, P.J. \& Anderson, D.K. (1988). Cognitive Flexibility: Advanced Knowledge Acquisition Ill-Structured Domains. In proceedings of the $\mathbf{1 0}^{\text {th }}$ Annual Conference of Cognitive Science Society, Erlbaum, Hillsdale, NJ, pg.375-383.

Spiro, R.J., \& Jehng, J.C. (1990). Cognitive Flexibility \& Hypertext: Theory \& Technology for the Nonlinear \& Multidimensional Traversal of Complex Subject Matter. In D. Nix \& R.J. Spiro (Eds.), Cognition, Education \& Multimedia: Exploring Ideas in High Technology. Hillsdale, NJ: Lawrence Erlbaum Associates.

Sherry, L., \& Myers, K.M. (1996). Developmental Research on Collaborative Design. In Proceedings of $43^{\text {rd }}$ Annual Conference of the Society for Technical Communication. Charlottesville, VA: Society for Technical Communication.

Weir, S. (1992). Electronic Communities of Learners: Fact or Fiction. In R. Tinker \& P. Kapisovsky (Eds.), Prospects for Educational Telecomputing: Selected Readings (Pg.87-110). Cambridge, MA: Technology Education Research Center. 
$5^{\text {th }}$ International Conference in Open \& Distance Learning - November 2009, Athens, Greece - PROCEEDINGS

Wilson, B \& Cole, P. (1994, April). An Instructional-Design Review of Cognitive Teaching Models. Paper presented at the meeting of the American Educational Research Association, Chicago, IL. 